\title{
REPRESENTAÇÕES SOCIAIS DO AMOR NO ROCK BRASILEIRO DOS ANOS 80
}

\author{
REPRESENTACIONES SOCIALES DEL AMOR EN EL ROCK BRASILEÑO DE \\ LOS ANONOS 80 \\ SOCIAL REPRESENTATIONS OF LOVE IN BRAZILIAN ROCK FROM \\ THE 1980'S
}

Adriano Roberto Afonso Nascimento, Luanda Carmo Queiroga, Luciana Celia da Silva Costa, Sara de Souza Campos e Gregório Ribeiro Miranda

Universidade Federal de Minas Gerais, Belo Horizonte/MG, Brasil

\begin{abstract}
RESUMO
O objetivo do presente trabalho foi descrever e analisar as Representações Sociais de amor no rock brasileiro dos anos 80. Foram consultados 222 LPs gravados e lançados entre 1981 e 1990, todos pertencentes ao rock brasileiro dos Anos 80. De um corpus inicial composto por 2.074 gravações, obtivemos 999 letras que faziam referência a relacionamentos amorosos (48,16\% do total). Dois procedimentos de análise foram utilizados: (a) Análise lexical (software ALCESTE) do corpus formado pelas 999 letras; e (b) análise de conteúdo de uma amostra $\left(\mathrm{E}_{0}=5 \%\right)$ de 286 letras que fazem parte desse corpus. Identificamos na análise lexical duas classes (Paisagem e Vou te dizer) que permitiram a articulação dos 09 conjuntos temáticos resultantes da Análise de conteúdo (Na pele, A paisagem, Ela, A luz, As sombras do amor, Só, Movimentos, No coração, Na cabeça). Identificamos tal articulação como o princípio organizador das Representações Sociais do amor no corpus analisado.
\end{abstract}

Palavras-chave: amor; representações sociais; rock brasileiro; anos 80 .

\section{RESUMEN}

El objetivo del presente trabajo fue describir y analizar las Representaciones Sociales del amor en el rock brasileño de los años 80. Fueron consultados 222 discos grabados y lanzados entre 1981 y 1990 , todos pertenecientes al rock brasileño. Desde un corpus inicial compuesto por 2.074 grabaciones, obtuvimos 999 letras que hacían referencia a relacionamientos amorosos $(48,16 \%$ del total). Dos procedimientos de análisis fueron utilizados: (a) Análisis lexical (software ALCESTE) del corpus formado por las 999 letras; y (b) Análisis de contenido de una muestra $\left(\mathrm{E}_{0}=5 \%\right)$ de 286 letras. Identificamos en el análisis lexical dos clases (Paisagem y Vou te dizer) que permitieron la articulación de los 09 conjuntos temáticos resultantes del análisis de contenido (Na pele, A paisagem, Ela, A luz, As sombras do amor, Só, Movimentos, No coração, Na cabeça). Identificamos tal articulación como el principio organizador de las Representaciones Sociales en el corpus analizado.

Palabras clave: amor; representaciones sociales; rock brasileño; años 80.

\begin{abstract}
This article aims at describing and analyzing the social representations of love within brazilian rock from the 1980s. 222 brazilian rock LPs recorded and released between 1981 and 1990 were analyzed. From an initial corpus consisting of 2074 recordings, 999 lyrics made reference to love relationship (48,16\% of total). Two analysis procedures were used: 1) Lexical Analysis (using the software ALCESTE) of the corpus (999 lyrics) and, 2) Content Analysis of a sample $\left(E_{0}=5 \%\right)$ of 286 lyrics that are part of this corpus. In the Lexical Analysis it was possible to identify two classes (Paisagem and Vou te dizer) that allowed the articulation of the 09 thematic groups resulting from Content Analysis (Na pele, A paisagem, Ela, A luz, As sombras do amor, Só, Movimentos, No coração, Na cabeça). This articulation was identified as the organizing principle of Social Representation of love in the corpus analyzed.
\end{abstract}

Keywords: love; social representations; brazilian rock; 1980s. 


\section{Introdução}

$\mathrm{O}$ interesse pelo entendimento do que é o amor é antigo e já produziu, ao longo dos séculos, inúmeros ensaios e tratados filosóficos (por exemplo, Bruckner, 2011; Capelão, 2000; Konder, 2007; Lewis, 2012; Rougemont, 1999, 2003; Stendhal, 1999). Mais recentemente, tal sentimento/objeto/categoria social também tem merecido atenção de diversas áreas das ciências humanas e sociais (Barthes, 1991; Bauman, 2004; Costa, 1998; Del Priore, 2005; Flandrin, 1988; Giddens, 1993; Kristeva, 1988), entre elas a psicologia social (Alferes, 2004; Brehm, 1985; García, 2002). Considerando-se as especificidades teóricas e metodológicas características das referidas áreas, a produção resultante desse interesse geral pelas relações amorosas tem propiciado um conjunto bastante diversificado de informações que, embora muitas vezes pouco articulado, tem abarcado fatores psicológicos, sociológicos e históricos que, indiscutivelmente, precisam ser considerados em uma abordagem interessada na significação social do amor.

Os parâmetros dessa significação social, baseada na conjugação dos fatores indicados, têm recebido diferentes nomes, como, por exemplo, no campo da história, "regime emocional" (Rosenwein, 2011) e "código de comunicação sensível" (Vincent-Buffault, 1988). Baseados na ideia de um compartilhamento mais amplo de elementos discursivos e emocionais que se entrelaçam para compor os significados sociais do amor em um dado momento histórico, tais conceitos guardam certa proximidade com o que, no campo da Psicologia Social, chamaríamos de Representações Sociais (Moscovici, 2004, 2012; Vidal, Rateau, \& Moliner, 2006) do amor.

As Representações Sociais, segundo Jodelet (2001), são, como fenômeno, "uma forma de conhecimento, socialmente elaborada e partilhada, com um objetivo prático, e que contribui para a construção de uma realidade comum a um conjunto social" (p. 22). De modo complementar, Jovchelovitch (2007) ressalta que, "como sistemas de entendimento compartilhado do mundo, as representações oferecem padrões de conhecimento e reconhecimento, disposições, orientações e conduta, que transformam ambientes sociais em lares para atores individuais e lhes permitem entender as regras do jogo" (p. 191).

Estudos realizados no nosso país sobre as Representações Sociais do amor têm indicado, considerando-se diferentes fontes, um conjunto de elementos que nos permitem começar a identificar quais seriam as "regras do jogo" amoroso na nossa sociedade (Costa \& Fernandes, 2012; Nascimento \& Martins, 2009; Nóbrega, Fontes, \& Paula, 2005). Esse conjunto de elementos encontra-se consistentemente organizado em função de polos bastante recorrentes na nossa forma de pensar e viver o amor: prisão/liberdade, felicidade/sofrimento, eu/outro, por exemplo. No cotidiano, são esses polos que possibilitam a comparação entre diferentes formas de se viver e de se falar sobre o amor. Assim, é no jogo dessas comparações, e na marca sobretudo normativa das conclusões delas resultantes, que os sujeitos sociais se situam, construindo para si pontos de referência eventualmente compartilhados que permitem atribuir sentido a sua própria forma de amar no interior de seu grupo de referência. Dessa maneira, como acontece com outros objetos de relevância social, é na dinâmica das relações intergrupais de uma dada sociedade, regida por questões ideológicas, éticas, morais e religiosas, que se constrói e se modifica o próprio objeto amor.

Se a construção e a modificação do objeto de uma Representação Social se dão em espaços de interação e de comunicação, devemos admitir que a canção popular pode ser uma fonte privilegiada para a identificação de elementos constituintes das Representações Sociais do amor em nossa sociedade.

Admitindo-se a existência de uma estreita relação entre aquilo que é vivido e aquilo que é cantado por seus intérpretes, a música popular, especialmente suas letras, vem ganhando progressivamente status de fonte válida para o entendimento de aspectos psicossociais por ela retratados (Menandro \& Nascimento, 2007).

Em relação ao nosso objeto de interesse, diversos estudos têm confirmado que o amor é tema privilegiado no nosso cancioneiro, destacando, de modo complementar, tanto a diversidade das formas de se amar em um mesmo período quanto um conjunto de elementos comuns que se mantêm através de diferentes épocas (Abreu, 2004; Alencar, 2006; Beltrão, 1993; Dias, 1994; Fontes, 1999; Gil, 2006; Matos, 1997; Matos \& Faria, 1996; Medina, 1973; Menandro, Pereira, Amim, \& Santos, 2003; Menezes, 2001; Paranhos, 2006; Pederiva, 2000).

Sendo o amor um tema privilegiado, no cotidiano e na canção popular, também as letras do rock brasileiro dos anos 80 tratam dele recorrentemente (Anaz, 2006; Silveira, 2008).

Interessados na veiculação de um discurso que fosse mais condizente com a linguagem de seus pares $^{1}$, os compositores e intérpretes do chamado rock brasileiro dos anos 80 investiram conscientemente na produção de canções acerca de assuntos do seu cotidiano com a utilização de uma linguagem também 
de uso comum (Alexandre, 2002; Bryan, 2004; Dapieve, 1995; Demarchi, 2008).

Entretanto, infelizmente, ainda são escassos os trabalhos que procuraram analisar os significados do amor veiculados durante esse período pelo referido estilo/movimento musical. Tal análise pode identificar elementos específicos que ajudaram a compor e retratar o "jogo amoroso" de parte de uma dada geração (Domingues, 2004; Mannheim, 1982; Peralva, 1997; ).

Assim, o objetivo do presente trabalho foi descrever e analisar as Representações Sociais de amor no rock brasileiro dos anos 80 .

\section{Método}

Foram consultados 222 LPs gravados e lançados entre 1981 e 1990, todos caracterizados como pertencentes ao chamado rock brasileiro dos anos 80. De um total de 2.194 fonogramas, excetuando-se as 39 regravações, as 47 músicas instrumentais e as 34 músicas cantadas em outros idiomas, chegamos a um corpus inicial composto por 2.074 gravações originais cantadas em português. Desse corpus inicial, integralmente transcrito, obtivemos 999 letras que faziam referência a relacionamentos amorosos $(48,16 \% \text { do total das letras transcritas })^{2}$.
Dois procedimentos foram utilizados para o tratamento de dados: (a) Análise lexical, realizada com o auxílio do software ALCESTE (Analyse Lexicale par Context d'un Ensemble de Segments de Texte) ${ }^{3}$ do corpus formado pelas 999 letras que possuem como temática os relacionamentos amorosos; e (b) Análise de conteúdo (Bardin, 1979; Vala, 2003) de uma amostra $\left(\mathrm{E}_{\mathrm{o}}=5 \%\right)$ de 286 letras que fazem parte desse corpus.

\section{Resultados}

Apresentaremos separadamente, e de modo bastante descritivo, os resultados obtidos nos dois procedimentos de análise de dados, deixando para a seção de discussão a consideração em conjunto dos resultados desses mesmos procedimentos.

\section{ALCESTE}

Duas classes de formas reduzidas foram geradas pela análise lexical das 999 letras que possuem como temática os relacionamentos amorosos (Figura 01). A primeira classe, nomeada Paisagem, agrupou, entre outras, as formas mar+ $\left(x^{2}=106,04\right)$, corpo $+\left(x^{2}=\right.$ $72,19)$, noit $+\left(x^{2}=55,61\right)$, rua $\left(x^{2}=58,06\right)$ e lua $+\left(x^{2}=\right.$ 49,93). A segunda classe, Vou te dizer, reúne, entre outras, as formas quer $+\left(x^{2}=102,19\right), \operatorname{diz}+\left(x^{2}=75,72\right)$, sei $\left(x^{2}=71,58\right)$, pod $+\left(x^{2}=53,92\right)$ e vai $\left(x^{2}=65,61\right)$.

\section{Figura 01. Classificação hierárquica descendente}

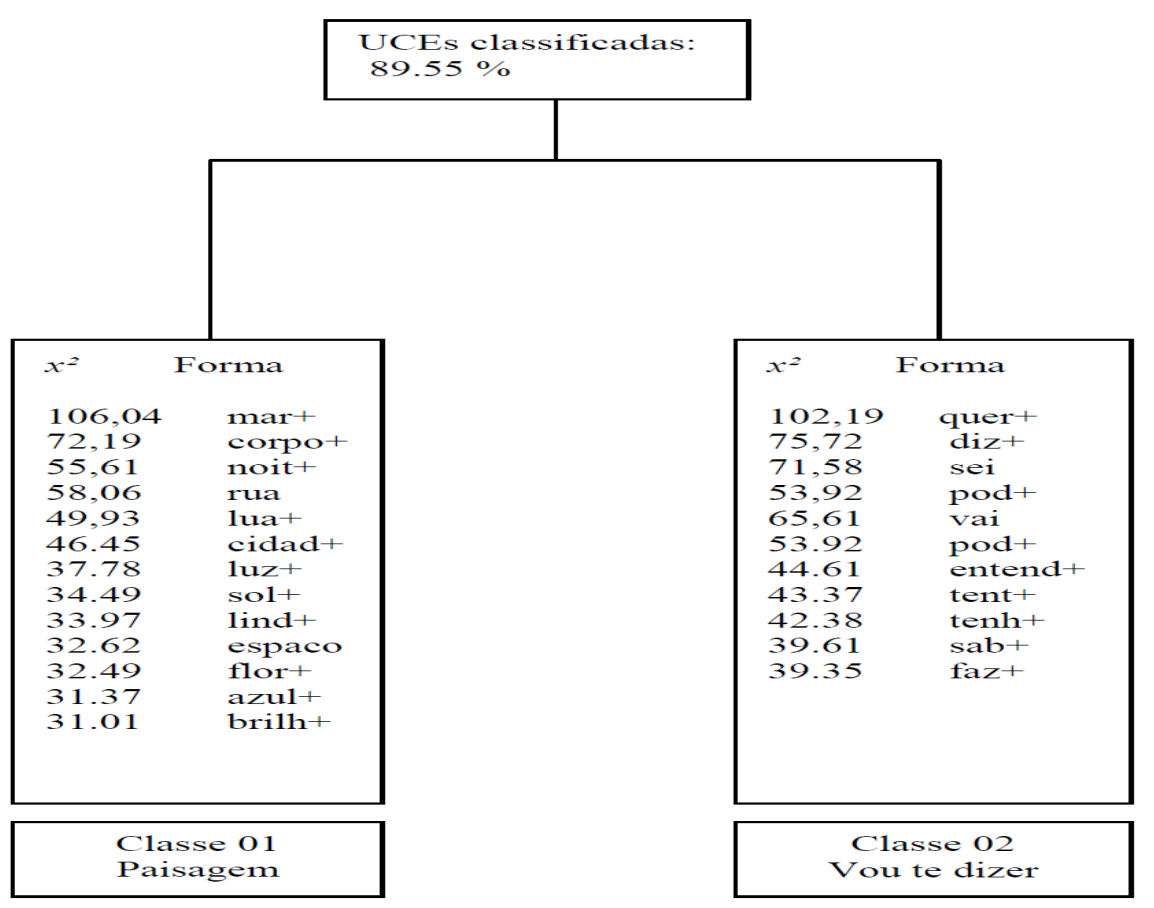


O programa ALCESTE gerou, além das listas de formas reduzidas pertencentes a cada classe, um conjunto de Unidades de Contexto Elementar (UCE) características que permite observar, em segmentos de textos submetidos à análise, a coocorrência das formas reduzidas das Classes 1 e 2.

Temos como UCEs características da Classe 1 (Paisagem):

nada. No céu, a lua é cheia, ela vira uma gata selvagem temida pelos mais temidos dos animais. Seu beijo é uma bomba de hidrogênio explodindo galáxias ${ }^{4} \cdot x^{2}=$ 30. Avião de combate (nada pode deter uma mulher feliz) (Joe Euthanázia \& Ronaldo Santos); 1984. Sempre Livres .

medo e mistério das trilhas no oásis do amor. A noite cai no deserto e nas tendas. A luz do fogo ilumina os corpos de belas nuas dançarinas. São vulcões de mel. $x^{2}=24$. Areias escaldantes (Lulu Santos); 1982. Lulu Santos.

Como UCEs características da Classe 2, temos:

Aconteceu assim. Assim como te digo. Muito tempo tive pra pensar, refazer a vida, aprender. Muitas coisas tive de mudar. Você disse isso para mim. Falta muito ainda para acabar. Acho mesmo que não existe fim. Tudo bem contigo. Pra ficar contigo, digo vou. $x^{2}=27$. Pra ficar contigo (Vinicius Cantuária); 1988. Ritchie.

Não me exponha, não me faça ruim, tenho muita coisa boa dentro de mim. Só você não sabe, só você não vê. Baby, desse jeito ninguém vai mais te querer. $x^{2}=$ 19. Só você não sabe (Kiko Zambianchi \& Zé Luiz Zambianchi); 1987. Kiko Zambianchi.

\section{Análise de conteúdo}

Com o objetivo de identificar, de modo mais preciso, os elementos presentes nas letras do rock brasileiro dos anos 80 que se referem às relações amorosas, submetemos à análise de conteúdo uma amostra de 286 letras que fizeram parte do corpus inicial $\left(\mathrm{E}_{0}=5 \%\right)$. Procedimentos da análise de conteúdo realizada: (a) Leitura flutuante do corpus; (b) Codificação; (c) Pré-categorização; (d) Categorização; (e)Agrupamento das principais categorias em conjuntos temáticos, objetivando um maior grau de abstração das referências; (f) Árvore Máxima da coocorrência dos conjuntos temáticos nas letras analisadas. Unidade de registro: tema. Unidade de Contexto: letra.

Na Tabela 01, em anexo, podem ser observadas as categorias pertencentes a cada um dos 09 conjuntos temáticos resultantes da análise (Na pele, A paisagem, Ela, A luz, As sombras do amor, Só, Movimentos, No coração, Na cabeça), bem como a sua frequência no corpus.

Os conjuntos temáticos que possuem maior presença no corpus analisado são as sombras do amor $(55,25 \%$ das letras analisadas), paisagem $(50,70 \%) \mathrm{e}$ na pele $(39,16 \%)$. Nesses mesmos conjuntos temáticos, encontram-se as 04 maiores categorias construídas: elementos naturais $(28,67 \%$ das letras analisadas), relação sexual $(22,73 \%)$, horário $(21,68 \%)$ e chorar, sofrer, tristeza $(21,33 \%)$.

Após a formulação dos conjuntos temáticos, procedemos à construção da árvore máxima, na qual podem ser observadas as coocorrências desses conjuntos nas letras das canções analisadas (Figura 2). Como poderá ser constatado, três conjuntos possuem grande coocorrência entre si e com os outros conjuntos. São eles: As sombras do amor, A paisagem e Ela.

Exibiremos, a seguir, 06 exemplos de letras nas quais pode ser visualizada a co-ocorrência dos conjuntos temáticos.

Coocorrência dos conjuntos temáticos Ela, A paisagem e As sombras do amor:

Luz dissolvendo o breu. Luz, você e eu. Na luz da anunciação, a chama de uma paixão. Tanto tempo no mar errei, tanto tempo procurando alguém. Tempo só, tempestade, a um passo da eternidade. Olhos claros vêm me clarear e a pureza vem me purificar, vem matar a saudade, a um passo da eternidade. Quis o mundo uma vez, quis. Ah, eu tive o que quis. Você, dinheiro, papéis. E agora foram-se os anéis. (A um passo da eternidade. Paulo Ricardo \& Fernando Deluqui, 1989)

Coocorrência dos conjuntos temáticos $\mathrm{Na}$ cabeça, Na pele e As sombras do amor:

Sem caminhos pra seguir na incerteza de chegar. Quem decide por partir só pensa em procurar um futuro com alguém, não importa o que passou, já nem se lembra mais, quer é recomeçar. Tantas vidas pra viver, tentando se encontrar. Tantas coisas por fazer pra se purificar. Não consigo mais sonhar, já me basta o que vivi sofrendo ao desejar quimeras que não consegui. Deuses do além, duendes do ar, anjos do bem vão te mostrar uma luz maior capaz de convencer que um mundo bem melhor existe em você só pro seu prazer. A força e o poder, sangue e suor de quem te fez viver, hoje eu sei por quê. Eu não vou mais fugir de mim! (Quimeras. Guilherme Isnard \& Zero, 1987)

Coocorrência dos conjuntos temáticos Ela, A paisagem e Na pele:

Navegando no teu mar, flutuando no teu ar, mergulhando em tua luz, vida... Deslizando no teu 
céu, me aquecendo em teu calor, penetrando no teu corpo. Ela veio assim, meio a fim de mim, eu não disse nem que sim, nem não. Garota dourada, quero ser teu irmão, eu sou teu irmão, namorado. Um beijo na boca, um abraço apertado, forte e suado, quente como as noites quentes do verão que brindamos quando nos demos as mãos. (Garota Dourada. Wander Taffo, Lee Marcucci, \& Nelson Motta, 1981)

Coocorrência dos conjuntos temáticos As sombras do amor, Só e A paisagem:

Verão, primavera, outono e inverno. O tempo passou, o sol se foi, as chuvas pararam de cair. Você partiu pra longe daqui e me deixou assim, sozinho, pensando, deitado no meu jardim. Eu tenho momentos tristes. Eu tenho momentos de prazer. Lembrando momentos agradáveis, quando estava junto de você. Todas as estações do ano. Eu lembro você no inverno, naquele casaco escuro. Eu penso em você no outono e vejo as folhas a cair. Eu lembro você na primavera, você era a flor que eu vi no chão. Se ainda estiver vivo, eu quero te ver é no verão. (Estações. Marcelo Z., Andrés, Bidi, \& Supla, 1985)

Coocorrência dos conjuntos temáticos A luz, As sombras do amor e a Paisagem:

Com toda certeza, bela por ser veloz, chegando junto. Veloz a beleza. Chega sem avisar e toca o fundo. Foi você atravessar o meu caminho, para sempre a esperança renasceu. Já colhi espinhos, hoje tenho um mar de rosas. Tudo que eu pedi o amor me deu. Só não tolero indecisão. Espero da paixão fazer de cada mestre um aprendiz. Sendo a teu lado meu país, é lá que arde o eterno verão. Falando a verdade, sou de brincar de amor levando a sério. A felicidade, quando se é feliz, não tem mistério. Os teus olhos refletidos nos meus olhos. Encontrei um pedacinho do céu. E, em cada estrela, vi que na longa espera tanto me perder não foi em vão. (O eterno verão. Ritchie \& Ronaldo Bastos, 1988)

Coocorrência dos conjuntos temáticos $\mathrm{Na}$ pele, As sombras do amor e A paisagem:

Seu corpo me deu e me tirou a razão. Sou escravo do prazer, do seu charme tão severo. Sou capaz de enfrentar nossa vida por você. De me dar sem receber, solução pros meus complexos. Além dos usos e virtudes, além das leis, além das guerras, dos medos, pragas e ciúmes. Além dos mitos e das trevas, arrisco loucuras, brincando com você. Deixando, no absurdo, um mundo tão blasé. Com a dose secreta de tudo que é bom, fabulosa imperfeição, de magias e mistérios. Te amo pelo sim e pelo não. Por um flash de ilusão, raios de sol numa cela. (Arrisco loucuras. "Don" Beto \& Virginie, 1988)

Passaremos, a seguir, à discussão desse conjunto de resultados.

\section{Figura 02. Árvore máxima de coocorrência de conjuntos de categorias (AC)}

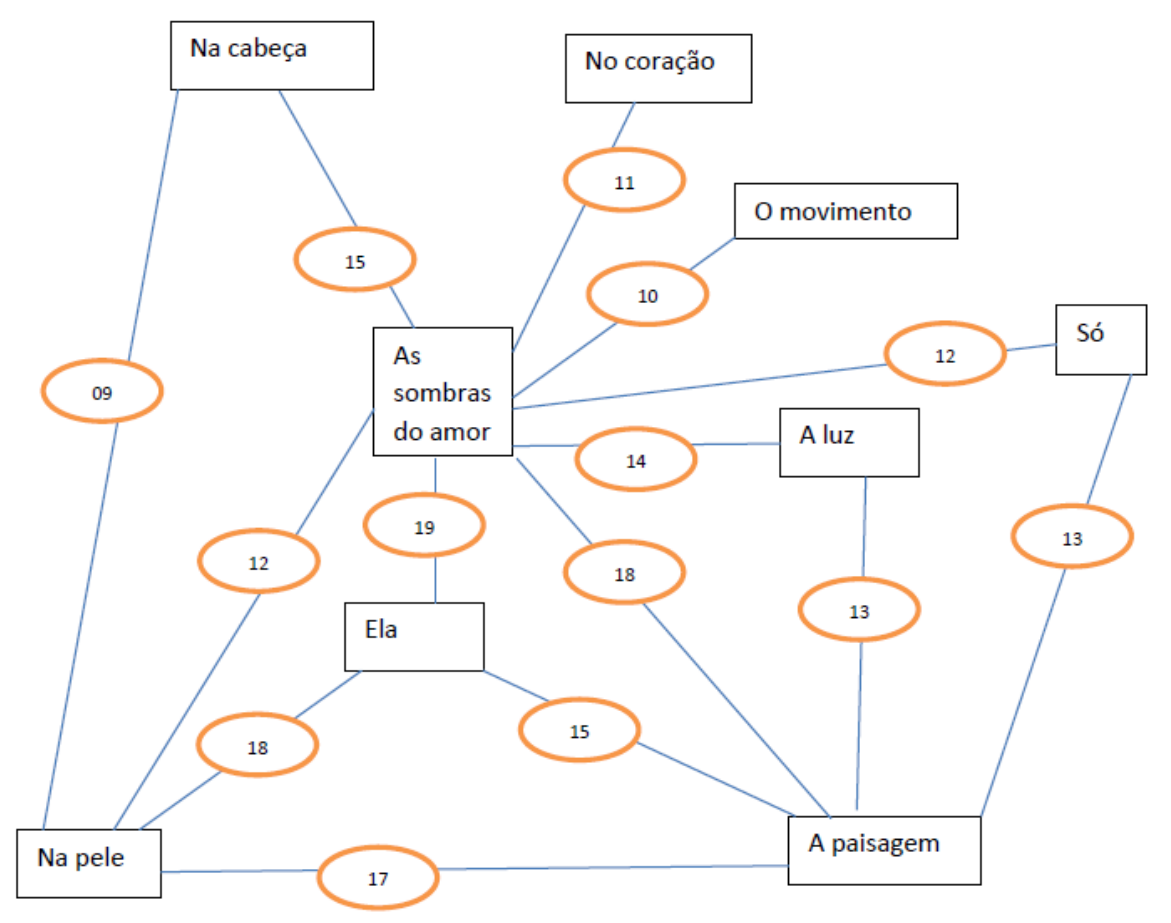




\section{Discussão}

As Representações Sociais do amor no rock brasileiro dos anos 80 organizam-se a partir de dois eixos. O primeiro deles, observado na Classe 1 do ALCESTE, descreve a Paisagem na qual se desenvolve o enredo amoroso. Estão aí agrupados os elementos do contexto mais próximo dos compositores, misturandose os elementos naturais sol, mar, lua e vento à vida frequentemente noturna e urbana (identificados na Análise de Conteúdo). Quanto a tal contexto, as letras analisadas são sobretudo descritivas e possibilitam, de forma coerente, a percepção de um amor vivido na pele. As numerosas menções à relação sexual dão prova dessa percepção e constituem referência significativa para se caracterizar o corpus. O amor cantado nesse momento não era o amor apenas sonhado e idealizado, como o foi em outros momentos da música popular no Brasil, era o amor vivido. Tal amor vivido é também amor falado para a mulher amada.

O segundo eixo sobre o qual se organiza o discurso amoroso analisado é a figura da interlocutora para a confissão, para o desabafo ou para o pedido de perdão (Classe 2 do ALCESTE). A respeito da amada, encontramos informações que, em certo sentido, aproximam-na da paisagem, pois o que é sobre ela descrito refere-se quase que exclusivamente às partes do seu corpo, fato que também reitera o amor vivido na pele. Falar acerca do amor para a mulher amada, pois o amor nas letras é quase que exclusivamente heterossexual, faz da canção ao mesmo tempo veículo de comunicação privada e pública, expondo aspectos da intimidade do sujeito da canção para um público de pares. A exposição desses aspectos íntimos, principalmente aqueles relacionados ao que chamamos de "as sombras do amor", confirma a canção como espaço no qual o homem pode se mostrar frágil, sofredor e eventualmente "nas mãos" da amada (Oliven, 1987).

Como foi possível verificar nos resultados, ainda que o rock brasileiro dos anos 80 tenha como característica a veiculação de um discurso estruturado em uma linguagem cotidiana e trate de temas cotidianos (Alexandre, 2002; Bryan, 2004; Dapieve, 1995; Demarchi, 2008), seu conteúdo mantém-se fortemente ancorado na histórica díade amor e dor, ancoragem já vista em outros trabalhos sobre a canção popular brasileira (Dias, 1994; Gil, 2006; Nascimento \& Martins, 2009) e sobre as Representações Sociais do amor na atualidade (Costa \& Fernandes, 2012; Nóbrega, Fontes, \& Paula, 2005). Essa díade, que se concretiza no corpus analisado como alternância entre a felicidade (A luz) e o sofrimento (As sombras do amor), se dá em um conjunto de ações (mudança, ir embora, voltar, recomeçar) que objetiva o próprio amor como movimento natural, como o das marés ou do sol e da lua, e permite que, entre a cabeça (sonho, pensar, lembrar, esquecer) e o coração, ele se naturalize também como ato sexual, garantindo a articulação entre os eixos de significado aqui identificados.

A articulação coerente de tais eixos, evidenciada na Figura 2, pode ser considerada como o princípio organizador das Representações Sociais do amor no corpus analisado, permitindo, a partir do que é compartilhado, um considerável grau de variação individual no relato das experiências amorosas. Essa variação, que pode ser vista na coocorrência apresentada dos conjuntos temáticos, possibilita a observação de uma das características mais importantes das Representações Sociais, que é a de ser, ao mesmo tempo, social e pessoal.

Lido em sua totalidade, o corpus analisado conjuga, além de referências sociais e pessoais articuladas, elementos mais recentes e mais tradicionais ainda presentes em nossa forma de construir o objeto amor. É assim que convivem, por exemplo, o caráter transitório das relações amorosas avessas a compromissos que extrapolem a própria duração do sentimento (Bauman, 2004; Bruckner, 2011; Giddens, 1993) e a percepção do amor como redenção, como um "outro mundo" (Rougemont, 1999, 2003). Tais dados reiteram a percepção de que, na necessidade de uma teoria prática que nos permita entender e viver as relações amorosas, a construção do próprio objeto desse entendimento e desse viver se dá a partir do conjunto de elementos acessíveis na urgência do cotidiano e daqueles disponíveis na memória social de um dado grupo (Moscovici, 2012).

\section{Notas}

Conforme aponta Ribeiro (2009), “o roqueiro padrão desse período é concebido como homem, 'jovem', 'heterossexual', 'branco', de classe social abastada ou remediada, e habitante dos grandes centros urbanos ... Seu público, de modo geral, reconhecidamente tendeu a se concentrar nas camadas médias e altas brasileiras, assim como nos grandes centros" (p. 19).

2 Quanto ao gênero dos compositores: (a) canções compostas exclusivamente por compositores $=88,11 \%$, canções compostas exclusivamente por compositoras $=2,10 \%$ e parcerias entre compositores e compositoras $=9,79 \%$.

3 O software ALCESTE identifica coocorrências de palavras em segmentos de textos, indicando, através da composição de classes de palavras fortemente associadas em um determinado discurso, elementos da organização geral (estruturação e significados) do tema alvo desse mesmo discurso (Kalampalikis, 2003; Reinert, 2001). 
4 As palavras incluídas em cada uma das classes estão sublinhadas.

5 Título da canção (Compositores/as); ano de gravação. Intérprete.

\section{Referências}

Abreu, M. (2004). "Sobre mulatas orgulhosas e crioulos atrevidos": conflitos raciais, gênero e nação nas canções populares (Sudeste do Brasil, 1890-1920). Tempo, 8(16), 143-173.

Alencar, M. A. G. (2006). Crimes da paixão: valores morais e normas de conduta na música popular brasileira. ArtCultura, $8(13), 151-162$.

Alexandre, R. (2002). Dias de luta: o rock eo Brasil dos anos 80. São Paulo: DBA.

Alferes, V. R. (2004). Atracção interpessoal, sexualidade e relações íntimas. In J. Vala \& M. B. Monteiro (Coords.), Psicologia Social (6 ${ }^{\mathrm{a}}$ ed., pp. 125-158). Lisboa: Fundação Calouste Gulbenkian.

Anaz, S. (2006). Pop brasileiro dos anos 80: uma visão semiótica da poética das canções mais cultuadas. São Paulo: Mackenzie.

Bardin, L. (1979). Análise de conteúdo (L. A. Reto \& A. Pinheiro, Trads.). Lisboa: Edições 70.

Barthes, R. (1991). Fragmentos de um discurso amoroso (11 ${ }^{\mathrm{a}}$ ed., H. Santos, Trad.). Rio de Janeiro: Francisco Alves.

Bauman, Z. (2004). Amor líquido: sobre a fragilidade dos laços humanos (C. A. Medeiros, Trad.). Rio de Janeiro: Zahar.

Beltrão, S. (1993). A musa-mulher na canção brasileira. São Paulo: Estação Liberdade.

Brehm, S. S. (1985). Las relaciones intimas. In S. Moscovici (Org.), Psicología Social 2 (D. Rosenbaum, Trad., pp. 221236). Buenos Aires: Paidós.

Bruckner, P. (2011). O paradoxo amoroso. Ensaio sobre as metamorfoses da experiência amorosa (R. Janowitzer, Trad.). Rio de Janeiro: Difel.

Bryan, G. (2004). Quem tem um sonho não dança: cultura jovem brasileira nos anos 80. Rio de Janeiro: Record.

Capelão, A. (2000). Tratado do amor cortês (I. C. Benedetti, Trad.). São Paulo: Martins Fontes. (Original publicado no Século XII)

Costa, J. F. (1998). Sem fraude nem favor: estudos sobre o amor romântico. Rio de Janeiro: Rocco.

Costa, V. \& Fernandes, S. C. S. (2012). O que pensam os adolescentes sobre o amor e o sexo? Um estudo na perspectiva das Representações Sociais. Psicologia \& Sociedade, 24(2), 391-401.

Dapieve, A. (1995). BRock - O Rock Brasileiro dos Anos 80. São Paulo: Editora 34.

Del Priore, M. (2005). História do amor no Brasil. São Paulo: Contexto.

Demarchi, A. (2008). O poder das letras: Legião Urbana, juventude e experiência. In E. Giumbelli, J. C. V. Diniz, \& S. C. Naves (Orgs.), Leituras sobre música popular: reflexões sobre sonoridade e cultura (pp. 193-209). Rio de Janeiro: 7letras.

Dias, R. M. (1994). As paixões tristes: Lupicínio e a dor de cotovelo. Rio de Janeiro: Leviatã.

Domingues, J. M. (2004). Ensaios de sociologia: Teoria e pesquisa. Belo Horizonte: UFMG.
Flandrin, J. L. (1988). O sexo e o ocidente (J. Prongin, Trad.). São Paulo: Brasiliense.

Fontes, M. H. S. (1999). Sem fantasia: masculino-feminino em Chico Buarque. Rio de Janeiro: Graphia.

García, C. Y. (2002). El amor desde la Psicología Social: ni tan libres, ni tan racionales. Madri: Pirámide.

Giddens, A. (1993). A transformação da intimidade: sexualidade, amor e erotismo nas sociedades modernas (M. Lopes, Trad.). São Paulo: UNESP.

Gil, B. D. (2006). O amor no léxico de canções populares. Estudos Lingüísticos, 35, 402-411.

Kalampalikis, N. (2003). L'apport de la méthode Alceste dans l'analyse dês représentations sociales. In J. C. Abric (Org.), Méthodes d'étude des représentations sociales (pp. 147163). Paris: Érès.

Konder, L. (2007). Sobre o amor. São Paulo: Boitempo.

Kristeva, J. (1988). Histórias de amor (L. T. Motta, Trad.). Rio de Janeiro: Paz e Terra.

Lewis, C. S. (2012). Alegoria do amor. Um estudo da tradição medieval (G. Greggersen, Trad.). São Paulo: É Editora. (Original publicado em 1936)

Mannheim, K. (1982). O problema sociológico das gerações. In M. M. Foracchi (Org.), Karl Mannheim: Sociologia (E. Willems, S. Uliana, \& C. Marcondes, Trads., pp. 67-95). São Paulo: Ática. (Original publicado em 1952)

Matos, M. I. S. (1997). Dolores Duran: experiências boêmias em Copacabana nos anos 50. Rio de Janeiro: Bertrand Brasil.

Matos, M. I. S. \& Faria, F. A. (1996). Melodia e sintonia em Lupicinio Rodrigues: o feminino, o masculino e suas relações. Rio de Janeiro: Bertrand Brasil.

Medina, C. A. (1973). Música popular e comunicação. Petrópolis, RJ: Vozes.

Menandro, P. R. M. \& Nascimento, A. R. A. (2007). Análise de conteúdo de material documental pré-existente à investigação: o caso da música popular. In M. M. P. Rodrigues \& P. R. M. Menandro (Orgs.), Lógicas metodológicas: trajetos de pesquisa em psicologia (pp. 207-224). Vitória: PPG-PSI/UFES; Editora GM.

Menandro, P. R. M., Pereira, J. F., Amim, I. D., \& Santos, S. M. (2003). Aspectos do relacionamento amoroso presentes em letras de músicas dirigidas à camada popular urbana. Arquivos Brasileiros de Psicologia, 54(1), 03-19.

Menezes, A. B. (2001). Figuras do feminino na canção de Chico Buarque (2a ed.). Cotia, SP: Ateliê Editorial.

Moscovici, S. (2004). Representações sociais: investigações em psicologia social (P. A. Guareschi, Trad.). Petrópolis, RJ: Vozes.

Moscovici, S. (2012). A psicanálise, sua imagem e seu público (S. Fuhrmann, Trad.). Petrópolis, RJ: Vozes.

Nascimento, A. R. A. \& Martins, A. S. (2009). A saudade amorosa na canção brasileira: um estudo exploratório (19271964). Psicologia Argumento, 27, 161-173.

Nóbrega, S. M., Fontes, E. P. G., \& Paula, F. M. S. M. (2005). Do amor e da dor: representações sociais sobre o amor e o sofrimento psíquico. Estudos de Psicologia, 22(1), 77-87.

Oliven, R. (1987). A mulher faz e desfaz o homem. Ciência Hoje, 7(37), 54-62.

Paranhos, A. (2006). Além das Amélias: música popular e relações de gênero sob o "Estado Novo". ArtCultura, 8(13), 163-174.

Pederiva, A. B. A. (2000). Jovem Guarda: cronistas sentimentais da juventude. São Paulo: Nacional. 
Peralva, A. (1997). O jovem como modelo cultural. Revista Brasileira de Educação, (5-6), 15-24.

Reinert, M. (2001). Alceste, une méthode statistique et sémiotique d'analyse de discours; Application aux «Rêveries du promeneur solitaire». La revue française de psychiatrie et de psychologie médicale, 5(39), 32-36.

Ribeiro, J. N. (2009). Lugar nenhum ou Bora Bora? Narrativas do "rock brasileiro anos 80". São Paulo: Annablume.

Rosenwein, B. H. (2011). História das emoções: problemas e métodos (R. Santiago, Trad.). São Paulo: Letra e Voz.

Rougemont, D. (1999). Los mitos del amor (M. S. Crespo, Trad.). Barcelona: Kairós. (Original publicado em 1961)

Rougemont, D. (2003). História do amor no ocidente (P. Brandi \& E. B. Cachapuz, Trads., 2 ${ }^{\mathrm{a}}$ ed). São Paulo: Ediouro. (Original publicado em 1939)

Silveira, J. R. (2008). Renato \& Cazuza: a poética da travessia - rock e poesia nos anos 80. São João del-Rey, MG: Malta Editores.

Stendhal, M. H. B. (1999). Do amor (R. L. Ferreira, Trad.). São Paulo: Martins Fontes. (Original publicado em 1822)

Vala, J. (2003). A Análise de Conteúdo. In A. S. Silva \& J. M. Pinto (Orgs.), Metodologia das ciências sociais (12 ${ }^{\mathrm{a}} \mathrm{ed} ., \mathrm{pp}$. 101-128). Porto: Afrontamento.

Vidal, J., Rateau, P., \& Moliner, P. (2006). Les Représentations en Psychologie Sociale. In N. Blanc (Dir.), Le concept de représentation en psychologie (pp. 11-42). Paris: In Press Éditions.

Vincent-Buffault, A. (1998). História das lágrimas: Séculos XVIII-XIX (L. Marques \& M. Gambini, Trads.). Rio de Janeiro: Paz e Terra.

\section{Fonogramas citados}

Beto, D. \& Virginie (1988). Arrisco loucuras [Gravado por Virginie e o Fruto Proibido]. Em Virginie e o Fruto Proibido [Meio de gravação: LP]. Rio de Janeiro: CBS/Epic.

Cantuária, V. (1988). Pra ficar contigo [Gravado por Ritchie]. Em Pra ficar contigo [Meio de gravação: LP]. Rio de Janeiro: Philips.

Euthanázia, J. \& Santos, R. (1984). Avião de combate (nada pode deter uma mulher feliz) [Gravado por Sempre Livre]. Em Avião de combate [Meio de gravação: LP]. Rio de Janeiro: CBS/Epic.

Isnard, G. \& Zero (1987). Quimeras [Gravado por Zero]. Em Carne humana [Meio de gravação: LP]. Rio de Janeiro: EMI/Odeon.

Marcelo Z., Andrés, Bidi \& Supla (1985). Estações [Gravado por Tokyo]. Em Humanos [Meio de gravação: LP]. Rio de Janeiro: CBS/Epic.

Ricardo, P. \& Deluqui, F. (1989). A um passo da eternidade [Gravado por Paulo Ricardo]. Em Paulo Ricardo [Meio de gravação: LP]. Rio de Janeiro: CBS/Epic.

Ritchie \& Bastos, R. (1988). O eterno verão [Gravado por Ritchie]. Em Pra ficar contigo [Meio de gravação: LP]. Rio de Janeiro: Philips.
Santos, L. (1982). Areias escaldantes [Gravado por Lulu Santos]. Em Tempos Modernos [Meio de gravação: LP]. Rio de Janeiro: WEA.

Taffo, W.; Marcucci, L. \& Motta, N. (1981). Garota Dourada [Gravado por Rádio Táxi]. Em Rádio Táxi [Meio de gravação: LP]. Rio de Janeiro: CBS/Epic.

Zambianchi, K. \& Zambianchi, Z. L. (1987). Só você não sabe [Gravado por Kiko Zambianchi]. Em Kiko Zambianchi [Meio de gravação: LP]. Rio de Janeiro: EMI/Odeon.

\section{Agradecimento}

Auxílio financeiro: Conselho Nacional de Desenvolvimento Científico e Tecnológico/CNPq. Edital Universal MCT/CNPq 14/2010, Processo 476924/2010-3.

Submissão em: 26/01/2013

Aceite em: 19/02/2014

Adriano Roberto Afonso Nascimento é psicólogo Social. Possui mestrado e doutorado em Psicologia pela Universidade Federal do Espírito Santo (2000 e 2004). Atualmente é Professor Associado do Departamento de Psicologia da Universidade Federal de Minas Gerais e professor-orientador do Programa de Pós-Graduação em Psicologia/FAFICH/UFMG. Interesses teóricos: representações sociais, identidade social e memória social.

Desenvolve atualmente investigações sobre os seguintes temas: saudade/nostalgia, saúde dos homens e música popular brasileira. Bolsista Produtividade em

pesquisa do CNPq. E-mail: nascimentopsi72@gmail.com

Luanda Carmo Queiroga é discente do Programa de PósGraduação em Psicologia/UFMG.

E-mail: luandaqueiroga@gmail.com

Luciana Celia da Silva Costa é discente do Curso de Graduação em Psicologia/UFMG.

E-mail: 1uluzinha_celia@hotmail.com

Sara de Souza Campos é discente do Programa de PósGraduação em Psicologia/UFMG.

E-mail:sara.souzacampos@gmail.com

Gregório Ribeiro Miranda é discente do Programa de PósGraduação em Psicologia/UFMG. E-mail:gregsmiranda@gmail.com 
Anexo

Tabela 01. Conjuntos de categorias e categorias por frequência e porcentagem

\begin{tabular}{|c|c|c|c|}
\hline Conjunto & Categoria & Frequência & $\%$ \\
\hline \multirow[t]{16}{*}{ As sombras do amor } & & 158 & 55,24 \\
\hline & Chorar, sofrer, tristeza & 61 & 21,33 \\
\hline & Mentir, enganar & 35 & 12,24 \\
\hline & Morte & 28 & 9,79 \\
\hline & Medos & 22 & 7,69 \\
\hline & Escravidão, prisão & 19 & 6,64 \\
\hline & Traição & 19 & 6,64 \\
\hline & Ilusão & 17 & 5,94 \\
\hline & Amor\&dinheiro & 15 & 5,24 \\
\hline & Casamento & 11 & 3,85 \\
\hline & Saudade & 8 & 2,80 \\
\hline & Brigar & 6 & 2,10 \\
\hline & Ciúmes & 6 & 2,10 \\
\hline & Silêncio & 6 & 2,10 \\
\hline & Amor não correspondido & 5 & 1,75 \\
\hline & Que saco & 4 & 1,40 \\
\hline \multirow[t]{7}{*}{ A paisagem } & & 145 & 50,70 \\
\hline & Elementos naturais & 82 & 28,67 \\
\hline & Horário & 62 & 21,68 \\
\hline & Bebida & 24 & 8,39 \\
\hline & Rua & 22 & 7,69 \\
\hline & Contexto sócio-político & 18 & 6,29 \\
\hline & Estações do ano & 8 & 2,80 \\
\hline \multirow[t]{5}{*}{ Na pele } & & 112 & 39,16 \\
\hline & Relação sexual & 65 & 22,73 \\
\hline & Abraços, beijos, carinhos & 49 & 17,13 \\
\hline & Prazer & 19 & 6,64 \\
\hline & Desejo & 17 & 5,94 \\
\hline \multirow[t]{6}{*}{ A luz } & & 88 & 30,77 \\
\hline & Apaixonar-se & 36 & 12,59 \\
\hline & Outro mundo & 25 & 8,74 \\
\hline & Felicidade & 21 & 7,34 \\
\hline & Sorrir & 14 & 4,90 \\
\hline & O amor redime & 11 & 3,85 \\
\hline \multirow[t]{5}{*}{ Na cabeça } & & 84 & 29,37 \\
\hline & Sonho & 39 & 13,64 \\
\hline & Esquecer & 24 & 8,39 \\
\hline & Lembrar & 22 & 7,69 \\
\hline & Pensar & 20 & 6,99 \\
\hline \multirow[t]{5}{*}{ Ela } & & 78 & 27,27 \\
\hline & Partes do corpo & 46 & 16,08 \\
\hline & Corpos & 23 & 8,042 \\
\hline & Características físicas da mulher amada & 14 & 4,90 \\
\hline & Características não físicas da mulher amada & 14 & 4,90 \\
\hline \multirow[t]{5}{*}{ Movimentos } & & 53 & 18,53 \\
\hline & Mudança & 24 & 8,39 \\
\hline & Foi embora & 17 & 5,94 \\
\hline & Voltar & 11 & 3,85 \\
\hline & Recomeçar & 6 & 2,10 \\
\hline \multirow[t]{3}{*}{ Só } & & 51 & 17,83 \\
\hline & Solidão & 35 & 12,24 \\
\hline & Sem caminhos pra seguir, incerteza & 20 & 6,99 \\
\hline \multirow[t]{2}{*}{ Coração } & & 41 & 14,34 \\
\hline & Coração & 41 & 14,34 \\
\hline
\end{tabular}

